Research, Society and Development, v. 7, n. 8, p. 01-22, e678329, 2018

ISSN 2525-3409 (CC BY 4.0)

\title{
Competências leitoras no ensino superior
}

\section{Reading competences in undergraduation course}

Celso Leopoldo Pagnan

Universidade Norte do Paraná, Brasil

E-mail: celso.pagnan@unopar.br

Márcia Cristiane Canguçu Rodrigues de Souza

Universidade Norte do Paraná, Brasil

E-mail: marciacangucu@hotmail.com

Recebido: 21/03/2018 - Aceito: 23/04/2018

\section{Resumo}

Este artigo tem por objetivo discutir as competências leitoras dos estudantes do Ensino Superior. Os exames nacionais de avaliação de desempenho são referências de análise. Entende-se que as Instituições de Ensino Superior devem voltar sua atenção para promoção da formação integral dos seus acadêmicos, desenvolvendo habilidades de leitura e de escrita em práticas sociais. É notória a pluralidade cultural manifestada no ambiente acadêmico e práticas de multiletramento podem contribuir para melhor aproveitamento do ensino, mais qualificação para o mundo do trabalho e ativo exercício da cidadania. Trata-se de uma pesquisa descritiva e exploratória, com procedimento, conjugado ao estudo de campo. Como instrumento de coleta de dados, utilizamos questionário para traçar perfil do público, e aplicamos um conjunto de questões extraídas de provas do ENADE, em cinquenta participantes. A discussão é ampliada com contribuições teóricas de Rojo (2004), Kleiman (2002), entre outros autores, no sentido de refletir sobre a importância da leitura e suas estratégias.

Palavras-chave: Competência; leitura; letramento; avaliação; ensino superior.

\begin{abstract}
This article aims to discuss the readers skills of college students. National performance assessment tests are analytical references. The undergraduation course institutions should turn their attention to promoting the students integral formation, developing reading skills and also writing in social practices. The remarkable cultural diversity manifested in the academic environment and litteracies practices can contribute to better use of education, more skills for work and active citizenship. It is a descriptive and exploratory research, with procedure,
\end{abstract}


combined with the field study. As a data instrument, we used a questionnaire to draw a profile of the public, and applied, to fifty participants, a set of questions extracted from ENADE test. The discussion is expanded with theoretical contributions of Rojo (2004), Kleiman (2002), among others, in to reflect the importance of reading and their strategies.

Keywords: Competence; reading; literacy; evaluation; higher education.

\section{Introdução}

Este artigo tem como objetivo investigar questões a respeito das competências leitoras dos acadêmicos do ensino superior, mais especificamente a habilidade em estabelecer relações entre o texto verbal e não verbal.

A aquisição do código de leitura é primordial, mas não basta para transitar em todos os contextos letrados. $\mathrm{O}$ ato de ler é decodificação das letras do alfabeto, porém sem conceber a leitura como prática social, não há sentido. É preciso construir significado para a leitura, para assim constituir uma leitura crítica.

O fato é que não basta apenas saber ler e escrever, é preciso saber fazer uso dessas habilidades: compreender e usar textos, verbais ou não, como mapas, tabelas, charges, fotografias, entre outros. Fazer uso de diferentes tipos e gêneros de textos, compreendê-los, interpretá-los e extrair informações. As imagens visuais podem ser lidas como um texto, pautado nos seus contextos sociais. São social e ideologicamente construídas, produzem conhecimento, formas de pensar e de agir no e com o mundo. São portadoras de sentidos que direcionam comportamentos, constituem relações de significado a partir de sua composição.

Além disso, há uma relação direta entre as competências leitoras e o desenvolvimento acadêmico. Estudantes do Ensino Superior que não possuem competências leitoras e não estejam em estado permanente de letramento apresentam maiores dificuldades no desenvolvimento acadêmico. As Instituições de Ensino Superior adotam diferenciados processos seletivos, mas teoricamente assumem compromisso com a formação dos aprovados.

Um modo de aferir o desenvolvimento de habilidades bem como das competências leitoras são os exames nacionais de avaliação de desempenho que, entre seus objetivos, analisam a capacidade de ler e interpretar diferentes gêneros textuais.

É o caso do Exame Nacional de Desempenho dos Estudantes (ENADE), cujo foco é avaliar os acadêmicos do Ensino Superior em relação aos conteúdos programáticos previstos nas diretrizes curriculares, às habilidades e competências para a atualização permanente e aos 
conhecimentos sobre a realidade brasileira, mundial e sobre outras áreas do conhecimento. Importante destacar que subjaz a todo esse conteúdo exatamente as práticas leitoras.

\section{Fundamentação teórica}

Vivemos em uma sociedade letrada, isto é, atribuir significado ao que se lê é demasiadamente importante, sendo indispensável para formação integral e desenvolvimento pleno do ser humano. É possível afirmar que a competência leitora pode incluir ou excluir o indivíduo na sociedade.

Para Tardif e Dubois (2012), competência, de modo geral, é um saber-agir complexo em um grupo de situações, apoiado na mobilização e combinação de recursos internos e externos. Já Perrenoud (1999a, p. 7) define competência como "capacidade de agir eficazmente em um determinado tipo de situação, apoiada em conhecimentos, mas sem limitar-se a eles”. De acordo com autor, competência não é uma implementação pura e simples de conhecimentos, mas o desenvolvimento de competências está atrelado ao conhecimento.

Quando as instituições de ensino proporcionam situações de leituras contextualizadas, oportunizam aos estudantes condições de se tornarem cidadãos, capazes de interferir no ambiente em que vivem. A competência de leitura possibilita ao aluno interagir com os outros, participando ativamente da vida em sociedade. Assim, é possível não mais ler somente para realização de trabalhos e/ou provas, mas ler como partícipes do mundo em construção.

Frequentar a leitura, captar sua voz, implica diversidade e profundidade. Desconsiderar essas características ao lidarmos com a formação do ser humano, tratando a/da leitura unilateralmente, ainda que com bons propósitos (como os de formarmos acadêmicos), implica o risco de destituirmos de sentido o ato de ler. Poderíamos dizer, também: nossa forma de lidar cotidianamente com a leitura não tem representado um convite ao leitor, para leva-lo a ler continuamente. Por conseguinte, não basta, na formação do ser humano, que tenhamos afinco em nossa proposta de conhecer ou de levar a conhecer, se o fazemos em sentido de mão única. Não é suficiente queremos aprender o Mundo apenas com o olhar da Ciência (ou de qualquer área do conhecimento que seja, tomada isoladamente). O ser humano que só lê e pensa a Ciência de modo ascético, desconsiderando outros saberes, é tão unilateral e incompleto como um artista que 
Research, Society and Development, v. 7, n. 8, p. 01-22, e678329, 2018

ISSN 2525-3409 (CC BY 4.0)

desconsidere outros saberes ao produzir sua obra de arte" (REZENDE, 2007, p. 5).

Muito mais do que decodificar o código, o indivíduo deve construir um sentido ao que lê. De acordo com Freire (2003, p. 11), leitura é o "ato de ler, que não se esgota na decodificação pura da palavra escrita ou da linguagem escrita, mas que se antecipa e se alonga na inteligência do mundo. A leitura do mundo precede a leitura da palavra."

É importante destacar ainda que há uma multiplicidade de códigos e linguagens que se conjugam. Estes são considerados também textos que conduzem a descobertas do mundo. Para Rezende (2007, p. 6), "há que se ler diferentes códigos, pois as várias leituras complementam-se, interligam-se, permitindo ao leitor novas tessituras". A leitura engloba conhecimento de mundo, de modo geral, como desenhos, símbolos, imagens etc.

Embora seja uma atividade inerente ao trabalho docente, professores revelam sua preocupação com o porquê de seus alunos não gostarem de ler, não sabem como promover condições em sala de aula para o desenvolvimento do leitor. Para Kleiman (2002, p. 7), “o ensino de leitura é fundamental para dar solução a problemas relacionados ao pouco aproveitamento escolar: ao fracasso na formação de leitores podemos atribuir o fracasso geral do aluno". Nota-se assim, a importância da competência leitora para o desenvolvimento acadêmico, independente da disciplina e/ou do curso.

A leitura não deve ser somente uma ação mecânica de decodificação. Da leitura da bibliografia exigida na disciplina fica apenas a obrigatoriedade de ler os livros no prazo estipulado pelo professor, para cumprir uma atividade. É comum, entre os professores, o comentário da falta de hábito e gosto pela leitura:

\footnotetext{
Alarmam-se os professores de Ciências, História e Geografia pelo fato seus alunos não lerem, e, no entanto, nada fazem para remediar essa situação. A palavra escrita é patrimônio da cultura letrada, e todo professor é, em princípio, representante dessa cultura. Daí que permanecer à espera do colega de Português resolver o problema, além de agravar a situação, consiste numa declaração de sua incompetência quanto à função de garantir a participação plena de seus alunos na sociedade letrada (KLEIMAN, 2002, p. 7).
}

Da mesma forma, Silva (2000, p. 16) afirma: “A leitura ocupa, sem dúvida, um espaço privilegiado não só no ensino da língua portuguesa, mas também no de todas as disciplinas acadêmicas que objetivam a transmissão de cultura e de valores para as novas gerações." Desenvolver a competência da leitura implica permear todas as etapas do ensino, e não apenas nas aulas voltadas à Língua Portuguesa, pois todas as demais disciplinas dependem da linguagem para desenvolver os aspectos conceituais. 
A leitura tem um caráter interdisciplinar e a sua promoção é uma responsabilidade de todo o corpo docente de uma instituição de ensino. Freire (2003, p. 11) diz que, "a compreensão do texto a ser alcançada por sua leitura crítica implica a percepção das relações entre o texto e o contexto". Além disso, não se pode reduzir o ato de ler, única e exclusivamente, pelo livro.

Para Silva (2000, p. 6), “a boa leitura é aquela que, depois de terminada, gera conhecimentos, propõe atitudes e analisa valores, aguçando, adensando, refinando os modos de perceber e sentir a vida por parte do leitor.” A leitura deve ser uma prática social intrínseca à vida cotidiana de todo aluno, uma atividade de construção de sentidos. Se o estudante tem a oportunidade de cultivar a leitura de forma ampla, se aprende a conviver no ambiente da leitura, consequentemente uma leitura levará a outra, até mesmo a acadêmica.

Segundo Rezende (2007, p. 4), “o prazer de ler carece, em seu desenvolvimento, de repertório cultural. Assim, as coisas se retroalimentam: quanto mais gostamos de ler, mais lemos e aumentamos o nosso repertório cultural. Dessa forma, quanto mais lemos, mais fácil fica a leitura." Formar competentes leitores exige um esforço contínuo por parte dos professores, até mesmo no Ensino Superior. É preciso capacitação contínua dos leitores no decorrer dos anos escolares. A leitura pode assim ser considerada uma aprendizagem ao longo de toda a vida.

Quando os professores das demais matérias se envolvem com o ensino de leitura, como deveriam fazê-lo, as oportunidades de criar objetivos significativos para a leitura de diversos textos se multiplicam. As oportunidades de diversificação e ampliação do universo textual do aluno são ilimitadas, desde que a atividade de leitura seja deslocada de uma atividade meramente escolar, sem outra justificativa a não ser cumprir programa, até uma atividade para cujo desenvolvimento e realização a leitura sirva como instrumento importante (KLEIMAN, 2002, p. 52).

A leitura depende de quem a faz, bem como do momento da vida em que é feita. Diferentes pessoas lendo o mesmo texto apresentarão variações quanto à sua compreensão e o que o leitor é capaz de aprender depende de conhecimentos anteriores. Para Rojo (2004), ler envolve diversos procedimentos e capacidades que dependem da situação e da finalidade, são estratégias de leitura. Antes, ler era visto de maneira simplista, como capacidade de decodificação. Com o desenvolver das pesquisas, outras capacidades foram desveladas ao ato de ler, buscando a compreensão do texto, bem como a interação entre o leitor e o autor. De acordo com a autora, recentemente a leitura é se colocar em relação ao discurso, possibilitando inúmeras réplicas.

Sobre estratégias, Kleiman (2002, p. 49) detalha: 
Quando falamos de estratégias de leitura, estamos falando de operações regulares para abordar o texto. Essas estratégias podem ser inferidas a partir da compreensão do texto, que por sua vez é inferida a partir do comportamento verbal e não verbal do leitor, isto é, do tipo de respostas que ele dá a perguntas sobre o texto, dos resumos que ele faz, de suas paráfrases, como também da maneira com que ele manipula o objeto: se sublinha, se apenas folheia sem se deter em parte alguma, se passa os olhos rapidamente e espera a próxima atividade começar, se relê.

As estratégias são classificadas como cognitivas, operações inconscientes do leitor para o processamento do texto apoiadas em vocabulário e gramática; e metacognitivas, operações conscientes do leitor, com objetivo traçado e flexibilidade de procedimentos para atingi-lo.

Dentro dessa visão do processo de leitura, isto é, como um conjunto de estratégias cognitivas e metacognitivas de abordagem do texto, o ensino estratégico de leitura consistiria, por um lado, na modelagem de estratégicas metacognitivas, e, por outro, no desenvolvimento de habilidades verbais subjacentes aos automatismos das estratégias cognitivas" (KLEIMAN, 2002, p. 50).

Para Rojo (2004, p. 4), “diferentes tipos de letramento, diferentes tipos de leitura, em diversas situações, vão exigir diferentes combinações de capacidades de várias ordens". Dentre as capacidades estão: decodificação, compreensão (estratégias), apreciação e réplica do leitor em relação ao texto (interpretação, interação).

As capacidades de decodificação são as mais básicas e as instituições de ensino geralmente focam somente estas capacidades, "é o que mostram os resultados de leitura de nossos alunos em diversos exames [...] tidos como altamente insuficientes para leitura cidadã numa sociedade urbana, globalizada, altamente letrada, como a atual” (ROJO, 2004, p. 4).

Avaliações, de modo geral, regulam as atividades desenvolvidas em sala de aula, bem como sua continuidade em outros níveis da educação. Avaliar é, para Perrenoud (1999a, p.9), “criar hierarquias de excelência, em função das quais se decidirão a progressão no curso seguido, a seleção no início do secundário, a orientação para diversos tipos de estudo, a certificação antes da entrada no mercado de trabalho e, frequentemente, a contratação."

A avaliação também pode proporcionar a melhoria da qualidade da educação, após análise dos resultados obtidos. Independentemente do objetivo inicial, e do nível de educação em que é aplicada, a avaliação se faz necessária e integra o processo de ensino-aprendizagem. Perrenoud (1999b, p. 13) ressalta que "em todos os casos, a avaliação não é um fim em si. É uma engrenagem no funcionamento didático e, mais globalmente, na seleção e na orientação escolares" 
Dentro desse contexto, e a fim de verificar as competências exigidas no ensino superior pelo Ministério da Educação (MEC), bem como o processo de sua avaliação ou medição, vamos tomar por referência para a discussão no presente trabalho o Exame Nacional de Desempenho dos Estudantes (ENADE), que tem suas diretrizes estruturadas por meio de competências, particularmente as leitoras.

O ENADE integra o Sistema Nacional de Avaliação da Educação Superior (SINAES), que também é composto pelos processos de Avaliação de Cursos de Graduação e de Avaliação Institucional. Junto com o ENADE forma um tripé avaliativo. Em 2004, a Lei no 10.861, instituiu o SINAES, a fim de assegurar o processo nacional de avaliação das instituições de Ensino Superior, além de melhorar a qualidade, orientar a expansão da oferta, aumentar eficácia institucional e efetividade acadêmica e social, bem como promover os compromissos sociais das instituições de Ensino Superior.

A realização do ENADE é de responsabilidade do Instituto Nacional de Estudos e Pesquisas Educacionais Anísio Teixeira (INEP), no entanto, conta com a orientação da Comissão Nacional de Avaliação da Educação Superior (CONAES), e apoio técnico de Comissões Assessoras de Área, de acordo com os cursos participantes de cada ano. Os exames são elaborados pelo INEP, a partir Banco Nacional de Itens da Educação Superior (BNI).

A Portaria Normativa n $^{\text { 40, de }} 12$ de dezembro de 2007, dentre diversas disposições, dispõe sobre o ENADE. Este é considerado um dos indicadores de qualidade, em conjunto com o Conceito Preliminar do Curso (CPC) e o Índice Geral de Cursos Avaliados da Instituição (IGC). De acordo com a portaria deve ser realizado anualmente, sendo aplicado aos estudantes de cada área por triênios, abrangendo assim, todos os cursos. Foi estabelecido um calendário, sendo ano I, cursos das áreas de saúde, ciências agrárias e áreas afins; ano II, cursos de ciências exatas, licenciaturas e áreas afins; e ano III, cursos de ciências sociais aplicadas, ciências humanas e áreas afins. Para os eixos tecnológicos, ficou estabelecido: ano I, Ambiente e Saúde, Produção Alimentícia, Recursos Naturais, Militar e Segurança; ano II, Controle e Processos Industriais, Informação e Comunicação, Infraestrutura, Produção Industrrial; ano III, Gestão e Negócios, Apoio Escolar, Hospitalidade e Lazer, Produção Cultural e Design.

O INEP solicita que as Instituições de Ensino Superior inscrevam estudantes ingressantes e concluintes do ano corrente dos cursos pré-determinados. O ENADE é um componente curricular obrigatório em todos os cursos superiores e deve constar no histórico 
escolar a participação ou a dispensa da prova de cada estudante em razão do calendário trienal.

Com o objetivo de aferir competências, habilidades e conteúdos agregados durante o curso de graduação, o ENADE é composto por uma prova de conhecimentos gerais e uma prova específica da área de formação. Faz também parte do ENADE, o preenchimento, por meio eletrônico, de um questionário que possibilita o conhecimento do perfil do estudante.

O ENADE tem como referência, os conteúdos programáticos previstos nas Diretrizes Curriculares de cada curso. A definição de diretrizes para as provas do ENADE é de atribuição do INEP. As comissões assessoras da formação geral, bem como, as comissões assessoras de áreas são responsáveis pelas definições das competências, conhecimentos, saberes e habilidades avaliadas. Na parte geral, o objetivo é aferir as habilidades leitoras do aluno, tanto de textos verbais, como de não verbais.

\section{Metodologia}

A presente pesquisa aborda questões relativas à aprendizagem no Ensino Superior, sistematizando o letramento não como habilidade técnica ou neutra, e sim como prática social, instrumento do exercício da cidadania e subsidio à formação integral da pessoa. $\mathrm{Na}$ busca por métodos e técnicas de pesquisa social para esta pesquisa foram utilizados conceitos de Gil (2014). Trata-se de uma pesquisa descritiva e exploratória tendo em vista a caracterização de um determinado fenômeno. A presente pesquisa proporciona uma nova visão do problema o que a aproxima da pesquisa exploratória, com objetivo de desenvolver, esclarecer e modificar conceitos e ideias. Por fim, quanto à abordagem, é qualitativa.

O procedimento utilizado é o bibliográfico, conjugado ao estudo de campo, na busca de aprofundamento da investigação de uma realidade específica. Para Gil (2002, p. 53) "o estudo de campo focaliza uma comunidade, que não é necessariamente geográfica, já que pode ser uma comunidade de trabalho, de estudo, de lazer ou voltada para qualquer outra atividade humana." Como instrumento de coleta de dados, utilizamos questionário para traçar perfil do público, e aplicamos um conjunto de questões extraídas de provas do ENADE.

A pesquisa problematiza as competências leitoras de alunos de uma Instituição de Ensino Superior privada do norte do Paraná. Nos estudos de campo, a preocupação é com a descrição, mas com maior ênfase na profundidade e não na precisão. De acordo com Gil (2002, p.132), "os estudos de campo requerem a utilização de variados instrumentos de pesquisa, tais como formulários, questionários, entrevistas e escalas de observação". 
Foram pesquisados cinquenta participantes, sendo vinte e cinco estudantes ingressantes de 2016 e vinte e cinco estudantes concluintes do mesmo ano, de cursos de bacharelado da Instituição. Todos os estudantes voluntários na pesquisa assinaram o Termo de Consentimento Livre e Esclarecido (TCLE). A identidade dos respondentes foi preservada, no entanto para identificação do perfil socioeconômico do público pesquisado foram aplicadas oito questões selecionadas das constantes no questionário do estudante que participa do ENADE, e foram acrescentadas duas questões, como complementação para detectar o perfil socioeconômico.

\section{Perfil dos estudantes}

Nesta seção, faremos a apresentação do perfil dos participantes da pesquisa. Quando for necessário para maior clareza, utilizaremos gráficos. Quando não, apenas informaremos os dados.

Dos estudantes pesquisados, $42 \%$ estão na faixa etária entre 20 e 29 anos, sendo $30 \%$ concluintes. A maior parte dos ingressantes, 34\%, têm 19 anos ou menos, ou seja, são estudantes que acabaram de concluir o Ensino Médio e imediatamente ingressaram no Ensino Superior. Como seria de se esperar, a maior parte dos concluintes tem uma faixa etária maior, visto que se trata de curso de quatro e cinco anos de duração. Há também os estudantes de 30 a 39 anos de idade, $12 \%$; de 40 a 49 anos, $8 \%$; e 50 a 59 anos, $2 \%$.

O hábito de leitura dos pais tem forte influência na construção do hábito de leitura dos filhos, principalmente a figura da mãe. Quanto maior o grau de instrução, maior o percentual de leitores, então a fim de analisar o grau de instrução dos pais e mães dos estudantes que fizeram parte da pesquisa foi questionado sobre a etapa de escolarização que eles concluíram. O grau de instrução dos pais é um pouco maior do que o das mães, conforme gráficos a seguir: 
Research, Society and Development, v. 7, n. 8, p. 01-22, e678329, 2018 ISSN 2525-3409 (CC BY 4.0)

Gráfico 1: Escolaridade materna

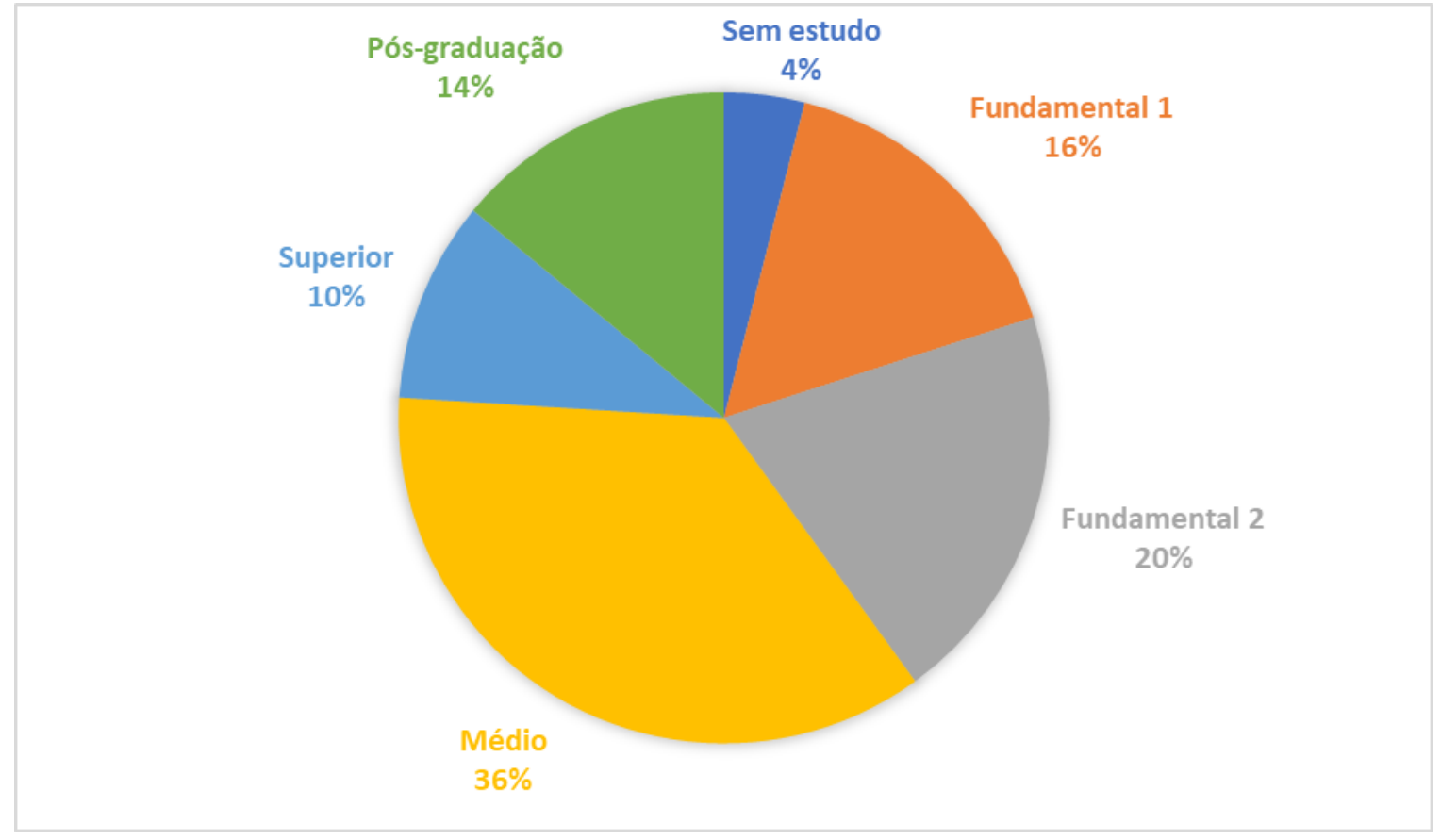

Fonte: dados da pesquisa

Gráfico 2: Escolaridade paterna

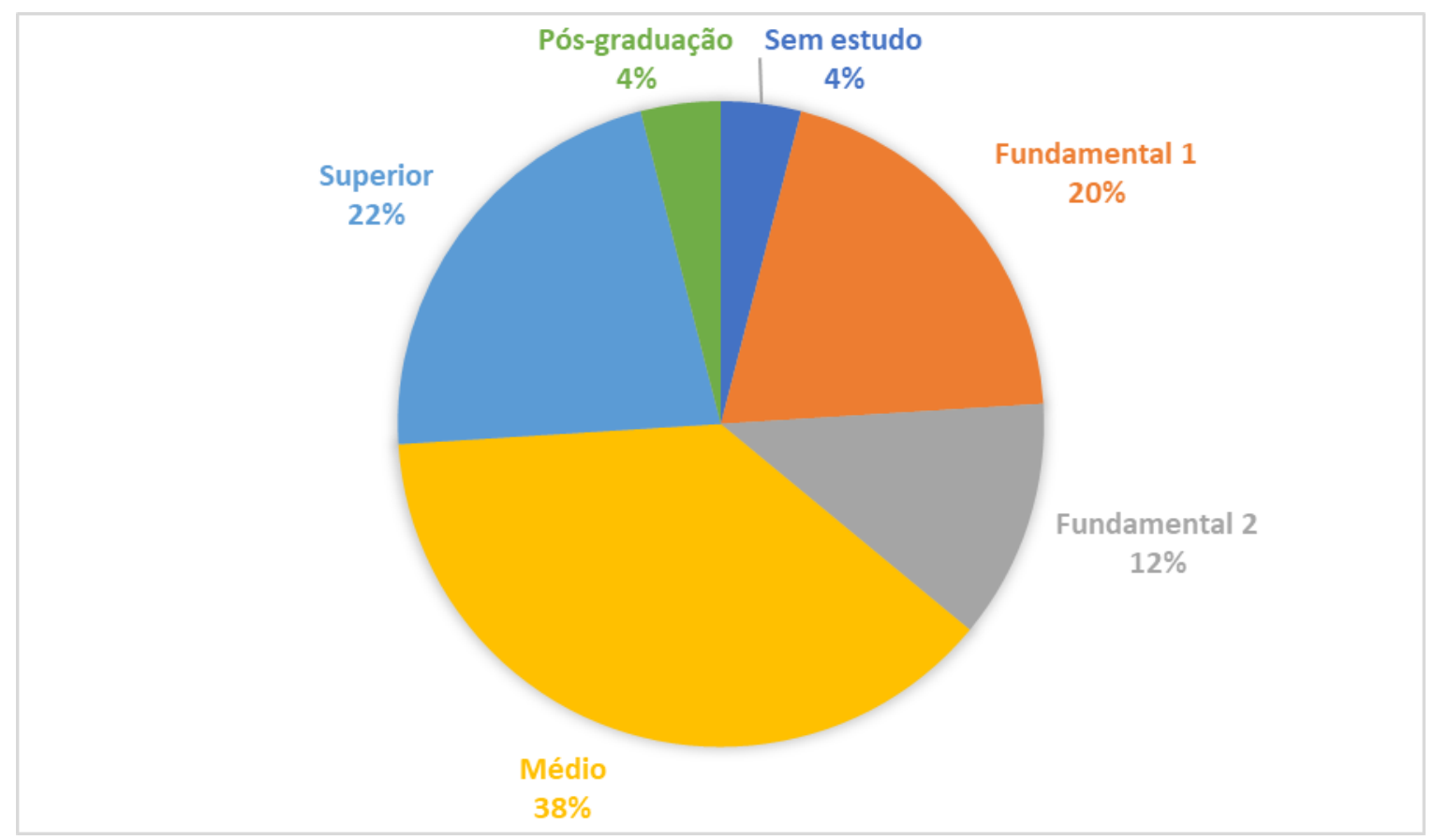


Fonte: dados da pesquisa

Tomando por referência os pais que concluíram do nível médio até a realização de uma pós-graduação, contamos, em termos absolutos, 32 indivíduos. No caso das mães, esse número cai para 30.

Outro dado dizia respeito à moradia dos participantes da pesquisa. Todos os estudantes pesquisados moram em casa ou apartamento, sendo que apenas 8\% (ou quatro estudantes) residem sozinhos. Como a maioria mora com os pais, supõe-se que haja uma cobrança maior para que o aluno desempenhe suas atividades acadêmicas com melhor aproveitamento. Embora o fato de se morar sozinho não seja, de per se, impeditivo para também se ter um bom desempenho.

Quanto ao local de residência, $80 \%$ dos estudantes pesquisados residem em cidades com população maior de 100 mil habitantes, o que significa que possuem infraestrutura suficiente para oferecer acesso à Educação. Os demais estudantes residem em cidades de pequeno porte. Entre os quais, $2 \%$ moram em cidades com menos de 5 mil habitantes; $8 \%$ em cidades com entre 5.001 e 10 mil habitantes; 2\% em cidades com entre 20.001 e 50 mil habitantes; $6 \%$, em cidades com entre 50.001100 mil habitantes.

Gráfico 3: Moradia dos estudantes

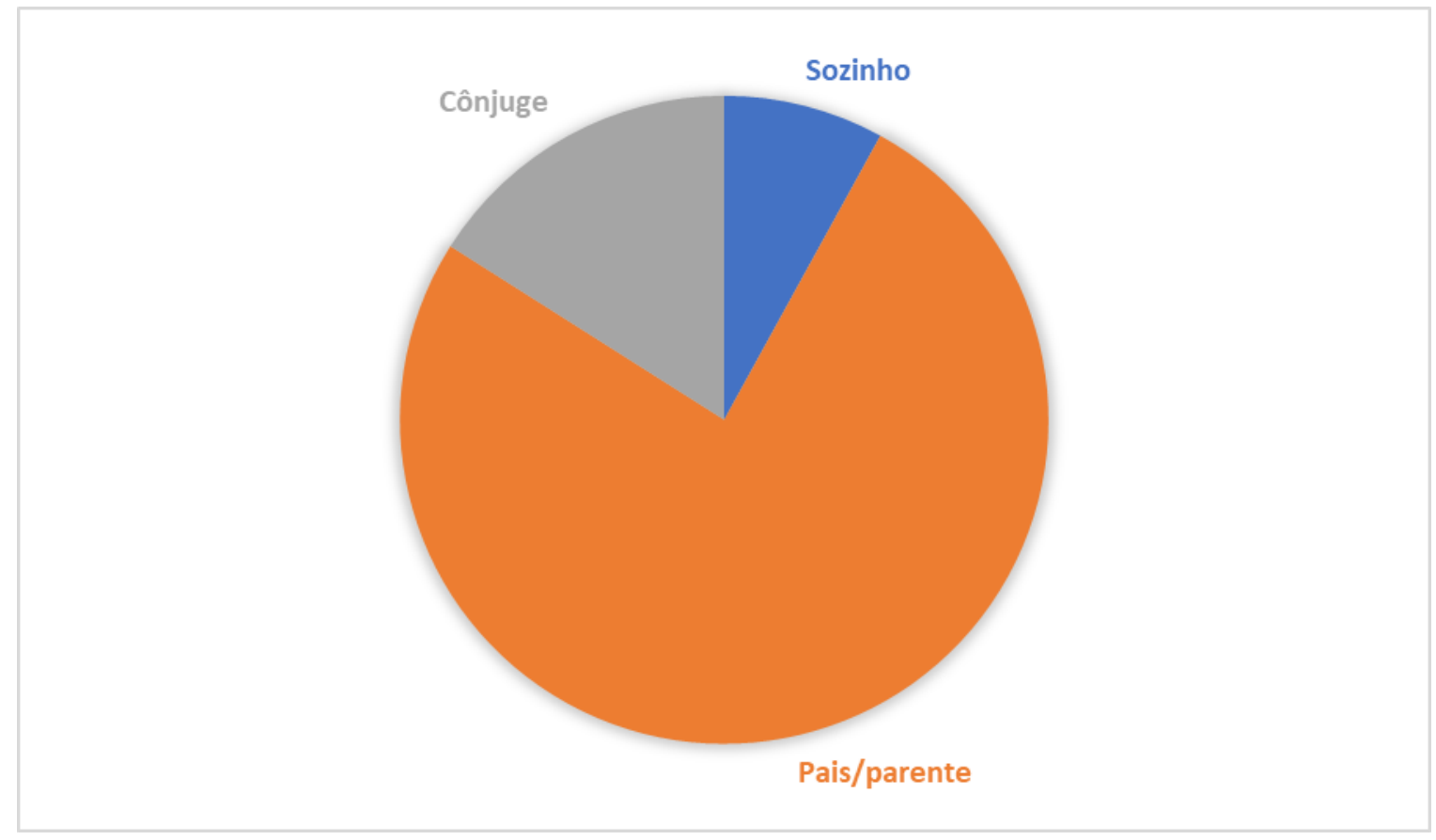

Fonte: dados da pesquisa 
Como possuem maior faixa etária, parte dos estudantes concluintes já formou suas famílias. Muitos dos estudantes pesquisados não residem na cidade onde a instituição de ensino é localizada, mas fazem o trajeto diariamente de transporte coletivo e podem desfrutar do convívio familiar como suporte para continuidade dos estudos.

Gráfico 4: Renda dos estudantes

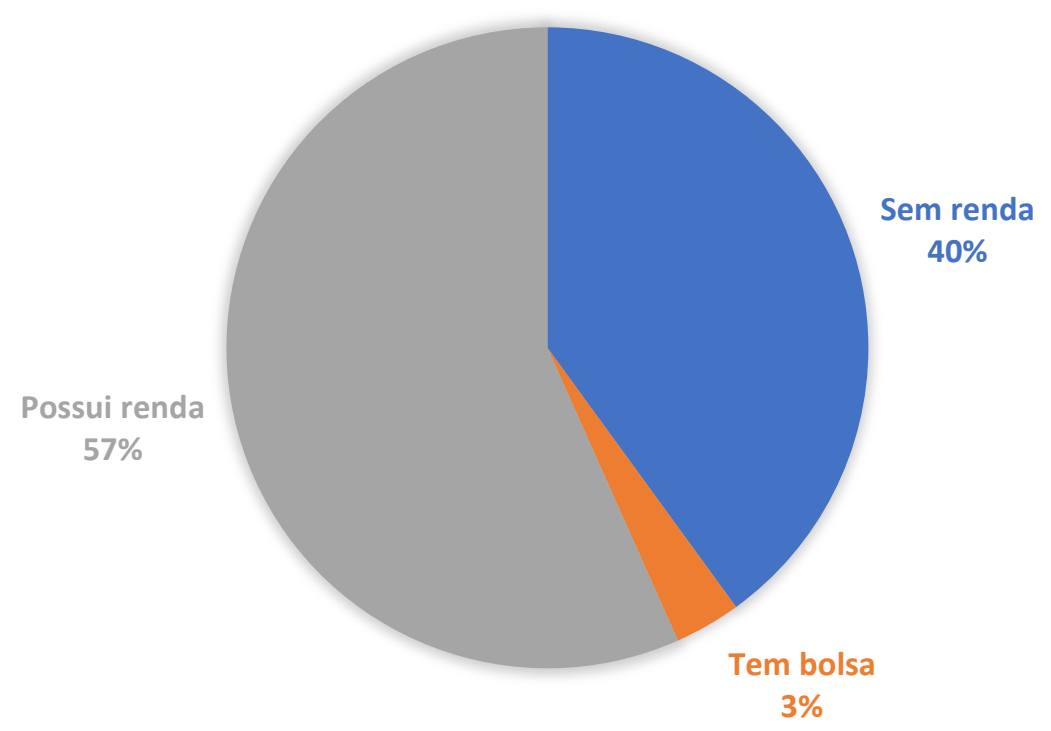

Fonte: dados da pesquisa

Desse total, $6 \%$ dizem não precisar de ajuda; $16 \%$ contribuem com o sustento da família; e $12 \%$ são principais responsáveis pelo sustento da família. Como parte dos estudantes concluintes já formaram suas famílias, contribuem e são responsáveis pelo seu sustento. Ou seja, dos 50 participantes da pesquisa, 16 têm renda que garantem o próprio sustento e de eventuais familiares.

Dos estudantes pesquisados, a maior parte cursou todo o Ensino Médio em escola pública, destes $28 \%$ são concluintes e $16 \%$ são ingressantes, totalizando $44 \%$. Já os estudantes oriundos de escolas privadas são, na sua maioria, ingressantes, $26 \%$ e concluintes, 14\%, totalizando $40 \%$. Há também os estudantes que fizeram o Ensino Médio parte em escola privada, parte em escola pública, $16 \%$.

Dos participantes da pesquisa, $82 \%$ concluíram a modalidade de Ensino Médio tradicional; $10 \%$ concluíram o Ensino profissionalizante técnico; 6\% a Educação de Jovens e 
Research, Society and Development, v. 7, n. 8, p. 01-22, e678329, 2018

ISSN 2525-3409 (CC BY 4.0)

Adultos (EJA) e/ou Supletivo; e 2\% outra modalidade. Supomos que o modelo tradicional oportuniza mais possibilidades de letramento, pelo contato constante com materiais didáticos.

Aspecto significativo para os objetos desta pesquisa é constatar que, quanto maior a renda, maior é o hábito de leitura de livros.

O Projeto Pedagógico do Curso (PPC) indica três livros como bibliografia básica. De acordo com os estudantes pesquisados, além dos livros indicados, informaram terem lido a seguinte quantidade de livros.

Gráfico 5: Média de livros lidos

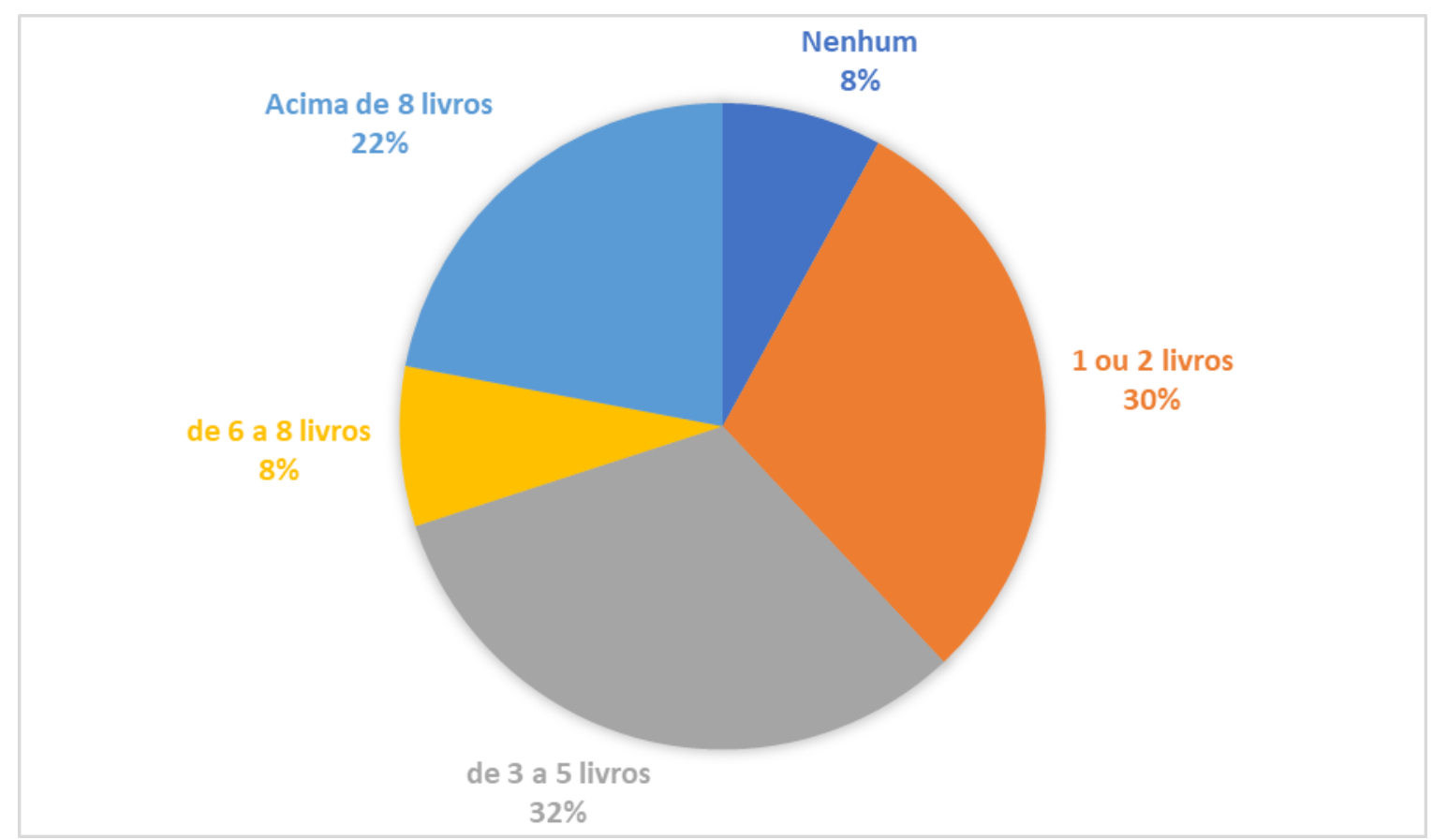

Fonte: dados da pesquisa

Desse total, podemos destacar ainda que, entre os $32 \%$ de alunos que declararam terem lido entre três e cinco livros (16 alunos em números absolutos), a maior parte (70\% do total, ou 11 alunos) eram ingressantes. Por outro lado, do total que declarou ter lido acima de oito livros (4 em números absolutos), três eram estudantes concluintes.

Evidente, por outro lado, que a mera quantidade diz pouco. O que importa mais é a qualidade e as razões da leitura.

Dentre as principais motivações para ler, além da exigência escolar, estão atualização cultural, crescimento pessoal e atualização profissional. O mundo do trabalho exige competência leitora. Para Freire (2003, p. 18), "a insistência na quantidade de leituras sem o devido adentramento nos textos a serem compreendidos, e não mecanicamente memorizados, 
revela uma visão mágica da palavra escrita. Visão que urge ser superada.” O problema maior está na qualidade da leitura e na capacidade de compreensão do que se lê.

Ler mais livros do que a bibliografia básica exige é importante, no entanto, mais do que simplesmente ler é preciso apropriar-se da leitura em suas práticas sociais. Ao adentrar em qualquer novo campo letrado, o indivíduo necessita de atenção diferenciada. Destacam-se assim as políticas de atendimento ao ingressante no Ensino Superior, pois há uma demanda do indivíduo e do meio, diante de um novo contexto.

De modo geral, a combinação entre comunicação verbal e não verbal precisa ser mais bem compreendida. Muitos e variados problemas nos sistemas educacionais podem ser elencados, no Brasil e no mundo. Para Freire (1996, p. 118), "um dos sérios problemas que temos é como trabalhar a linguagem oral ou escrita associada ou não à força da imagem, no sentido de efetivar a comunicação que se acha na própria compreensão ou inteligência do mundo."

A tarefa do educador é desafiar o educando, exigindo reflexão crítica e propiciando condições para o aluno assumir-se como ser social pensante e transformador. A prática docente precisa ser dinâmica e dialética, relação entre o fazer e pensar sobre o fazer. Para tanto, existem políticas que estimulam o desejo de aprender e de se desenvolver como pessoa e profissional. Competência leitora por meio do multiletramento deve ser uma delas.

Por outro lado, conforme iremos demonstrar na seção seguinte, embora afirmem que leram um número razoável de livros, os estudantes pouco conseguem extrair de informações relevantes para análise e interpretação das questões aplicadas. Pode-se afirmar que, tanto os ingressantes, mas, principalmente os concluintes, não possuem o letramento suficiente para um desempenho satisfatório neste nível de escolaridade. Em síntese, as competências leitoras seriam insuficientes.

\subsection{Análise do letramento}

Além da aplicação dessas dez questões para se obter o perfil socioeconômico, cinco questões de formação geral foram aplicadas aos estudantes, da mesma forma como apresentadas em ENADE anteriores para possibilitar a medição do letramento destes estudantes.

O Exame oficial geralmente é aplicado em um único caderno que contém primeiro as questões de formação geral e, posteriormente, as questões do componente específico da área 
de formação do curso superior. O caderno contém tanto questões objetivas, de múltipla escolha, como questões subjetivas, discursivas.

O caderno do ENADE é feito com impressão colorida, permitindo melhor análise de imagens. Para cada questão subjetiva, são quinze linhas para a resposta discursiva, sendo que para correção, há um padrão de resposta. Para cada questão objetiva, são cinco alternativas de respostas, identificadas como: a, b, c, d, e. Há apenas uma alternativa correta para cada questão. Para algumas questões objetivas, as alternativas das respostas referem-se a afirmações anteriormente feitas com base no enunciado da questão que devem ser avaliadas, podendo ser caracterizada como uma estrutura de respostas indiretas.

Para esta análise em particular, somente foi utilizada a formação geral, que corresponde a $25 \%$ do exame, destas $80 \%$ são objetivas. Para aprofundamento da pesquisa, foram aplicadas, interpretadas e analisadas cinco questões objetivas de exames dos dois últimos anos, 2014 e 2015. Foram selecionadas questões de acordo com a competência IV do ENADE no que diz respeito à formação geral, sendo ela "interpretar diferentes representações simbólicas, gráficas e numéricas de um mesmo conceito". As representações são textos nãoverbais e, como texto, sua linguagem precisa ser decodificada e analisada conforme contexto social. As questões apresentam representações simbólicas, gráficas e numéricas. De acordo com Dionísio é:

[...] importante mencionar que ao conceber os gêneros textuais como multimodais, não estou atrelando os aspectos visuais meramente a fotografias, telas de pinturas, desenhos, caricaturas, por exemplo, mas também à própria disposição gráfica do texto no papel ou na tela de computador (DIONÍSIO, 2006, p. 133).

Na primeira questão, correspondente a questão número 03 do ENADE 2014, que trata do meio ambiente, $54 \%$ dos estudantes pesquisados acertaram a resposta. No entanto, a diferença de acertos de ingressantes e concluintes é mínima: $26 \%$ e $28 \%$ respectivamente.

A desigualdade de gênero era tema da segunda questão, que corresponde à questão 06 do ENADE 2014. Nela, os estudantes ingressantes tiveram melhor desempenho do que os concluintes. Dos $60 \%$ de acertos, $32 \%$ são dos alunos que ingressaram na faculdade em 2016 e $28 \%$ são dos alunos que já concluirão o curso superior.

A responsabilidade social corporativa era tema da terceira questão, que corresponde também a questão número 3 do ENADE 2015. Esta foi a questão que obteve menor número de acertos. Somente $40 \%$ dos estudantes participantes da pesquisa acertaram a questão, sendo $14 \%$ ingressantes e $26 \%$ concluintes. 
A quarta questão, correspondente à questão número 5, da formação geral do ENADE 2015, tratava de emprego para mulheres. Os estudantes participantes da pesquisa tiveram o melhor desempenho nesta questão: $72 \%$ acertam a questão, sendo $34 \%$ estudantes ingressantes e $38 \%$ estudantes concluintes.

Já a quinta questão, que corresponde à questão número 8 do ENADE 2015, abordava o grafite como expressão de arte e meio de comunicação. $52 \%$ dos estudantes pesquisados acertaram a questão. 24\% são estudantes ingressantes e $28 \%$ são estudantes concluintes.

Fazendo uma análise comparativa dos acertos dos estudantes ingressantes e dos concluintes é possível afirmar que a diferença de desempenho é muito pequena, sendo que em uma das questões o desempenho dos estudantes concluintes foi inferior ao dos ingressantes. Em média, os estudantes ingressantes acertaram 2,60 das cinco questões aplicadas, enquanto os estudantes concluintes, acertaram 2,96 das mesmas questões. Questiona-se então se o estudante concluinte teria condições de participar de uma prova de sua classe profissional, de concorrer em um concurso, ou ainda, de fazer parte do mundo do trabalho. Por mais que exista diferença no perfil socioeconômico das turmas, o resultado ficou aquém do esperado. Pode-se afirmar que os estudantes concluintes estão no mesmo patamar que os ingressantes.

Para Rojo (2004, p. 1), “a maior parcela de nossa população, embora hoje possa estudar, não chega a ler.” As práticas de leitura nas instituições de ensino, seja ela básica ou superior, não desenvolvem as capacidades envolvidas nas práticas letradas exigidas em sociedade.

Por mais que haja a competência leitora em parte dos estudantes ao ingressar no Ensino Superior, o processo de estímulo de leitura de texto e contexto precisa ser contínuo. $\mathrm{O}$ letramento deve ser permanente para o bom desempenho como acadêmico, mas principalmente para o exercício da cidadania e desenvolvimento da sociedade.

Para Perrenoud (2000), desigualdade e fracasso escolar são problemas sociais, e não tem como profissionais da educação serem indiferentes às diferenças. A preocupação com as características individuais surge do respeito às pessoas e bom senso pedagógico. O desafio é propor interações entre os alunos, sem impedir uma individualização da trajetória de cada um.

Embora, esteja sob análise o sistema de ensino brasileiro, esta realidade é comum em todas as nações. Para Perrenoud (2000, p. 18), ela é presente em todas as sociedades, "as desigualdades reais de capital cultural apresentam-se, primeiramente, como capacidades desiguais de compreensão e de ação, revelando um poder desigual sobre as coisas, os seres e as ideias."

O autor defende uma pedagogia diferenciada a fim de atenuar as desigualdades: 
Não se pode imaginar uma abordagem por competências que não seja facilmente sensível às diferenças, a partir do momento em que os alunos são colocados em situações em que, supostamente, aprendem fazendo e refletindo sobre os obstáculos encontrados (PERRENOUD, 2000, p. 95).

A abordagem por competências permite individualizar o ensino, possibilitando o desenvolvimento de habilidades do indivíduo, mesmo em atividades coletivas. De acordo com Perrenoud, o motor de um grupo é a heterogeneidade. "O desafio está em reunir, frente a uma mesma situação de aprendizado, alunos de níveis diferentes, sem que isso favoreça, sistematicamente, os favorecidos (PERRENOUD, 2000, p. 97).

Em se tratando em mudança de nível de ensino, a circunstância é ainda mais complicada, sendo necessária uma atenção diferenciada, bem como, valorização do conhecimento prévio do aluno. Para Perrenoud:

Ligar o desconhecido ao conhecido, o inédito ao já visto, está na base de nossa relação cognitiva com o mundo; porém, a diferença está em que, às vezes, a assimilação ocorre instantaneamente, a ponto de parecer confundirse com a própria percepção da situação e, outras vezes, precisa-se de tempo e de esforços, ou seja, de um trabalho mental, para apreender uma nova realidade e reduzi-la, ao menos em certos aspectos e de maneira aproximativa, a problemas que se sabe resolver (PERRENOUD, 2000, p. 29).

As práticas de letramento dependem do contexto e não podem ser tratadas como neutras ou técnicas. Se assim fossem, ao aprender decodificar letras em palavras, palavras em sentenças, qualquer indivíduo poderia transitar no mais complexo contexto letrado.

Destaca-se também que é fundamental considerar não somente a comunicação verbal, mas também a comunicação não-verbal. O processo de construção de conhecimentos, por meio da utilização de representações simbólicas é necessário. As pessoas precisam, a todo momento, fazer uso de múltiplos letramentos associados a diferentes contextos. $\mathrm{Na}$ atualidade, cada vez mais as pessoas estão sujeitas à leitura de textos que combinam escrita e imagens. São diferentes modalidades como produtoras de sentido.

As práticas de multiletramento podem contribuir para a capacidade de atribuir e produzir sentidos a mensagens multimodais como fotos, desenhos e ilustrações. Elas podem também ser compreendidas como instrumentos para o exercício da cidadania. A sociedade está cada vez mais visual, assim torna-se imprescindível analisar a inter-relação entre texto escrito, imagens e outros elementos gráficos. Além de possibilitar a compreensão dos sentidos sociais construídos por esses textos, a sua importância nas práticas de letramento. 
Quando estão presentes gêneros multimodais como tiras, charges, propagandas, e não considerados seus elementos visuais, a compreensão do todo do enunciado pode ser prejudicado. Dionísio (2006) sugere multiletramentos para designar a capacidade de atribuir e produzir sentidos a mensagens multimodais. Defende letramento plural que concilie o letramento imagético (signo visual) e o letramento da escrita (signo verbal). Uma pessoa letrada é capaz de atribuir sentidos a mensagens oriundas de múltiplas fontes de linguagem.

Não basta enfatizar letramentos, pois o mundo exige multiletramentos. Viver demanda competência leitora de mapas, infográficos, linhas do tempo, gráficos, tabelas, fotografias, obras de arte, croquis, histórias em quadrinhos, tirinhas, charges, propagandas, planta baixa etc.

As imagens visuais podem ser lidas como um texto, pautado nos seus contextos sociais. São social e ideologicamente construídas, produzem conhecimento, formas de pensar e de agir no e com o mundo. São portadoras de sentidos que direcionam comportamentos, constituem relações de significado a partir de sua composição.

Para tanto, são necessárias práticas que estimulem a produção e interpretação de textos multimodais. Práticas de linguagem no espaço escolar devem ser focadas em letramentos múltiplos. Segundo o referido autor (2006, p.132), "na sociedade contemporânea, à prática de letramento da escrita, do signo verbal, deve ser incorporada a prática de letramento da imagem, do signo visual." Assim, é necessário abordar letramento de forma plural.

É de extrema e fundamental importância e preciso considerar a pluralidade cultural do país e, consequentemente, as diferenças culturais do aluno, pois cada um traz consigo histórias diversificadas, muitas delas voltadas à limitação do ensino de regras ortográficas. Dessa forma, os estudantes ingressantes apresentam sérias dificuldades.

Estas dificuldades são mais presentes em estudantes vindos de níveis sociais mais baixos, que tem obtido acesso ao nível superior de escolaridade por meio de políticas de bolsas sociais. Mas, ao invés de focar os défices do estudante, uma abordagem utilizando o modelo letramentos acadêmicos coloca em primeiro plano a variedade e a especificidade das práticas e o fazer sentido destas.

O conhecimento tem que estar contextualizado, tem que estar relacionado com a realidade de mundo, país, cidade, bairro. Para Freire (1996, p. 28) "uma das bonitezas de nossa maneira de estar no mundo e com o mundo, como seres históricos, é a capacidade de, intervindo no mundo, conhecer o mundo". Exige-se assim, respeito aos saberes dos educandos, sobretudo aos das classes mais populares, estabelecendo relação entre os saberes fundamentais do currículo e a experiência social dos alunos como indivíduos. A identidade 
cultural, a experiência histórica, política, cultural e social, não pode ser menosprezada, mas também é preciso aceitar o novo e rejeitar qualquer forma de discriminação.

Não é possível respeito aos educandos, à sua dignidade, a seu ser formandose, à sua identidade fazendo-se, se não se levam em consideração as condições em que eles vêm existindo, se não se reconhece a importância dos 'conhecimentos de experiência feitos' com que chegam à escola. $\mathrm{O}$ respeito devido à dignidade do educando não me permite subestimar, pior ainda, zombar do saber que ele traz consigo para a escola (FREIRE, 1996, p. 64).

Os alunos ingressantes no Ensino Superior precisam de atenção, pois suas concepções de leitura e escrita nem sempre são suficientes para seus engajamentos nas práticas acadêmicas, isto porque, ao longo da trajetória escolar, foram submetidos a um modelo que não considera, nem leitura, nem escrita, como práticas sociais. Dessa forma, sentem dificuldades, quando se requer habilidades de leitura e escrita, não técnicas ou neutras.

Para Dionisio (2006, p. 142), “de acordo com a sofisticação e especialização dos gêneros de cada disciplina, diferentes especificações de multimodalidade textual são apresentadas e, consequentemente, diferentes letramentos são exigidos." As instituições de ensino devem se atentar à promoção e desenvolvimento de habilidades de leitura e escrita para que estudantes se tornem indivíduos mais aptos ao mundo do trabalho. O letramento acadêmico pode ser entendido como uma nova abordagem para a compreensão da escrita que possibilita suprir diferenças culturais.

Não é concebível que existam lacunas no aprendizado, por meio de abordagens que desconsiderem a trajetória de letramento de cada indivíduo, como o modelo dos estudos das habilidades. Não é aceitável que se forme reprodutores de discursos e dificultem o avanço na formação de cidadãos para atuarem de forma efetiva na sociedade, como no modelo de socialização acadêmica. Ambos os modelos não privilegiam o desenvolvimento de estratégias de leitura e de escrita, apenas testam nível de compreensão em situações isoladas.

As demandas de letramento do currículo no ensino superior envolvem práticas comunicativas que variam com os cursos, considera a história de letramentos de cada indivíduo, bem como o processo de aculturação, como o modelo de letramento acadêmico. Os modelos de letramento não se excluem, eles se sobrepõem. Mais do que conhecer convenções que regulam as práticas de letramento, é preciso se ver como sujeito da linguagem e ser produtor de seus próprios discursos. Somente desenvolvendo habilidades de leitura e escrita específicas da esfera acadêmica para se engajar nos modos de uso da escrita da área. 


\section{Considerações finais}

O letramento atua a favor da autonomia dos educandos e precisa ser permanente, pois a inacabamento do ser humano faz com que ele fique em movimento contínuo de busca. Pode-se assim, afirmar que o letramento tem que ser inseparável da prática educativa, independente do público infantil, jovem ou adulto. Não se pode deixar tomar pelo conformismo ou acomodação.

O ensino é uma busca constante e exige criticidade e curiosidade. A curiosidade é vital, é ela que move as pessoas e acrescenta algo ao mundo. Sem curiosidade não há criatividade. Assim, é possível afirmar que é preciso desenvolver a curiosidade crítica.

Cada um constrói sua presença no mundo, com herança genética e também social, cultural e histórica. As práticas de multiletramento propõem que os indivíduos deixem de ser objetos da história, para serem sujeitos.

O papel do professor não é ensinar o conteúdo e sim incitar o aluno à compreensão. Os currículos, tanto do Educação Básica, quanto da Educação Superior, não devem definir conteúdos a serem ensinados, e sim as competências que devem construir. Destaca-se aqui que a leitura é compromisso de todas as áreas. O desenvolvimento da competência leitora é responsabilidade de todo o corpo docente de uma instituição de ensino. Assim, é preciso que se desenvolvam nos alunos do ensino superior competências leitoras que vão além da decodificação e da compreensão literal do que se lê. Trata-se de níveis em que se fica na superficialidade textual. Há que se possibilitar um aprofundamento da compreensão leitora, que o aluno seja capaz de inferir os significados e estabelecer relações entre o que lê o conhecimento de mundo de modo a revelar habilidade em discutir conceitos e de posicionarse a respeito da leitura, revelando-se capaz de "interpretar diferentes representações simbólicas, gráficas e numéricas de um mesmo conceito", conforme a competência IV da prova do ENADE, que serviu de base para a realização da presente pesquisa.

Em síntese, é papel do professor potencializar a aprendizagem significativa trabalhar as competências do aluno, dentre elas, as competências leitoras, estabelecendo ligações com a realidade, articulando vários elementos e promovendo o saber fazer e a entrega. A abordagem por conteúdos meramente conceituais gera um sujeito passivo. Com conceitos somados aos procedimentos e atitudes, tem-se o sujeito ativo com visão ampla de mundo, não só capaz de entendê-lo, mas de agir sobre ele. 


\section{Referências}

BRASIL, Decreto ${ }^{0} 5.773$ de 09 de maio de 2006. Instruções para elaboração de Plano de Desenvolvimento Institucional. Disponível em: <http://www2.mec.gov.br/sapiens/pdi.html> Acesso em: 20 ago. 2017.

BRASIL. Componente Formação Geral. Portaria Inep no 294 de 8 de junho de 2016. Disponível em <http://download.inep.gov.br/educacao_superior/enade/legislacao/2016/formacao_geral_porta ria_n294_08062016.pdf> Acesso em: 10 ago. 2017.

BRASIL. Lei no 9.394, de 20 de dezembro de 1996. Lei de Diretrizes e Bases da Educação Nacional. Disponível em: <http://portal.mec.gov.br/arquivos/pdf/ldb.pdf> Acesso em: 20 ago. 2017.

BRASIL. Lei no ${ }^{\circ}$ 10.861, de 14 de abril de 2004: Criação do Sistema Nacional de Avaliação da Educação Superior - SINAES. Disponível em: <http://www.planalto.gov.br/ccivil_03/_ato2004-2006/2004/lei/110.861.htm> Acesso em: 30 jan. 2017.

BRASIL. Manual ENADE 2016, publicado 25 de maio de 2016.MEC/INEP. Disponível em: <http://download.inep.gov.br/educacao_superior/enade/manuais/manual_do_enade_01072016 .pdf>. Acesso em: 30 mai. 2017

BRASIL. Ministério da Educação. Diretrizes Curriculares Nacionais Gerais da Educação. Brasília: MEC, SEB, DICEI, 2013. Disponível em: < http://portal.mec.gov.br/index.php?option=com_content\&view=article\&id=12986 >. Acesso em: 18 jan.2017.

BRASIL. Portaria Normativa $\mathrm{n}^{\mathbf{0}} 05$ de 09 de março de 2016. Exame Nacional de Desempenho dos Estudantes - ENADE 2016. Disponível em: <http://download.inep.gov.br/educacao_superior/enade/legislacao/2016/portaria_normativa_n 05_de_09032016.pdf>. Acesso em: 12 mar. 2017.

BRASIL. Portaria Normativa ${ }^{\circ}$ 40, de 2007, republicada 2010. Institui o e-MEC, sistema eletrônico de fluxo de trabalho e gerenciamento de informações relativas aos processos de regulação, avaliação e supervisão da educação superior no sistema federal de educação, e o Cadastro e-MEC de Instituições e Cursos Superiores e consolida disposições sobre indicadores de qualidade, banco de avaliadores (Basis) e o Exame Nacional de Desempenho de Estudantes (ENADE) e outras disposições. Disponível em: http://portal.mec.gov.br/index.php?option=com_docman\&view=download\&alias=16763port-norm-040-2007-seres\&category_slug=dezembro-2014-pdf\&Itemid=30192> Acesso em: 20 fev. 2017

BRASIL. Programa Internacional de Avaliação de Estudantes. Disponível em: http://portal.inep.gov.br/pisa-programa-internacional-de-avaliacao-de-alunos 
BRASIL. Parecer CNE/CES $n^{\circ} 776$, de 3 de dezembro de 1997. Orientações para as Diretrizes Curriculares dos cursos de graduação. Conselho Nacional de Educação. Disponível em: <http://portal.mec.gov.br/index.php?option=com_content\&view=article\&id=12986> Acesso em: 20 ago. 2017.

DIONISIO, Ângela P. Gêneros multimodais e multiletramento. In: KARWOSKI, A. M.; GAYDECZKA, B.; BRITO, K. S. (Orgs.) Gêneros textuais reflexões e ensino. Rio de Janeiro: Lucerna, 2006. p. 131-144.

FREIRE, Paulo. A importância do ato de ler: em três artigos que se completam. 45. ed., São Paulo: Cortez, 2003.

FREIRE, Paulo. Pedagogia da Autonomia: saberes necessários à prática educativa. São Paulo: Paz e Terra, 1996.

GIL, A. C. Como elaborar projetos de pesquisa. 4. ed., São Paulo: Atlas, 2002.

GIL, A. C. Métodos e técnicas de pesquisa social. 6. ed., São Paulo: Atlas, 2014.

KLEIMAN, Angela. Oficina de leitura: teoria \& prática. 9. ed., Campinas: Pontes, 2002.

LAJOLO, Marisa. Do mundo da leitura para a leitura do mundo. São Paulo: Ática, 1993.

PERRENOUD, Philippe. Avaliação: da excelência à regulação das aprendizagens entre duas lógicas. Porto Alegre: Artmed, 1999a.

PERRENOUD, Philippe. Construir as competências desde a escola. Porto Alegre: Artmed, 1999b.

PERRENOUD, Philippe. Pedagogia Diferenciada: das intenções à ação. Porto Alegre, Artmed, 2000.

REZENDE, Lucinea Aparecida de. Leitura na graduação: para apalpar as intimidades do mundo. In: REZENDE, Lucinea Aparecida de (Org.) Leitura e visão de mundo: peças de um quebra-cabeça. Londrina: EDUEL, 2007. p. 1-11.

ROJO, Roxane. Letramento e capacidades de leitura para a cidadania. São Paulo: SEE: CENP, 2004.

SILVA, Theodoro Ezequiel da. A produção da leitura na escola. 2. ed., São Paulo: Ática, 2000.

TARDIF, Jacques; DUBOIS, Bruno. Construir dispositivos para a avaliação do desenvolvimento de competências. Como? In: PAQUAIS, Léopold; NIEUWENHOVEN, Catherine; WOUTERS, Pascale (Orgs.) A avaliação como ferramenta de desenvolvimento profissional de educadores. Porto Alegre: Penso, 2012. p. 138-151. 